\title{
Informed participation in a randomised controlled trial of computed tomography screening for lung cancer
}

\author{
K.A.M. van den Bergh*, M.L. Essink-Bot*,\#, R.J. van Klaveren` and H.J. de Koning*
}

ABSTRACT: The actual lung cancer (screening) knowledge, attitudes, risk perceptions, reasons to participate in or decline participation, and informed decisions of subjects who decided to or decided not to participate in the Dutch-Belgian randomised controlled trial for lung cancer screening in high-risk subjects (the NELSON trial) were evaluated.

A total of 2,500 high-risk subjects were asked to complete a questionnaire 3 weeks after they had received a brochure with information about the trial. Differences in knowledge, attitude and risk perception between participants and nonparticipants were analysed with logistic regression analyses adjusted for sex and smoking status.

The questionnaire response of trial participants was $80 \%(n=889)$ whereas the response of nonparticipants was low $(7 \%, n=97)$ and selective. Participants' responses to knowledge items on lung cancer as a disease were on average more often correct (mean \pm SD $68 \pm 17 \%$ ) than items on lung cancer screening (49 $\pm 29 \%)$. Participants had adequate knowledge on lung cancer screening $(51 \%)$ more often than the nonparticipants $(38 \% ; p=0.009)$. Of the decisions regarding participation, $49 \%$ were uninformed, mainly due to insufficient knowledge. Most of the participants $(99 \%)$ and $64 \%$ of the nonparticipants had a positive attitude towards lung cancer screening.

Additional efforts are required to improve the knowledge and understanding of subjects who are in the process of decision-making regarding participation in a lung cancer screening trial.

KEYWORDS: Informed decision-making, knowledge, lung neoplasms, mass screening, participation

ung cancer is the leading cause of cancer deaths in males and the second-greatest cause of cancer deaths in females [1, 2]. Currently, lung cancer can be detected at an earlier stage by computed tomography (CT) screening [3]. Although the public demand and enthusiasm for screening are high [4], a reduction in mortality due to lung cancer screening has not yet been proven and the results of randomised controlled trials are still awaited [5-7].

An informed decision (or informed choice) is defined as a decision based on relevant information, whereas screening behaviour is consistent with the decision-maker's values [8,9]. Ideally, subjects make an informed decision to participate or not in a lung cancer CT screening programme [10] because this can have a positive effect on quality of life and reduce decisional conflicts [8, 11]. Although knowledge is a prerequisite for making an informed decision $[8,12,13]$, previous cancer screening studies have shown that this knowledge is often limited [14, 15].

In the current study, we examined subjects at high risk of developing lung cancer who were in the decision-making process regarding participation in the Dutch-Belgian randomised controlled trial for lung cancer screening in high-risk subjects (the NELSON trial).

The following questions were addressed:

1) What is the knowledge about lung cancer (screening), what are the attitudes, lung cancer risk perceptions, and the reasons to participate or decline participation in lung cancer screening among (non-) participants in the NELSON trial?

2) Can differences in knowledge among participants be explained by differences in sex and education?

3) To what extent is decision-making regarding participation in the NELSON trial based on an informed decision?

\section{MATERIALS AND METHODS NELSON trial}

Dutch and Belgian subjects registered in population registries and aged 50-75 yrs were sent a letter with an information leaflet and a first questionnaire (fig. 1) [7]. The two-sided paper

\section{AFFILIATIONS}

*Depts of Public Health, and

"Pulmonology, Erasmus MC,

University Medical Centre Rotterdam, Rotterdam, and

\#Dept of Social Medicine, Academic Medical Centre, University of Amsterdam, Amsterdam, The Netherlands.

CORRESPONDENCE

K.A.M. van den Bergh

Dept of Public Health, Erasmus MC University Medical Centre Rotterdam P.0. Box 2040

3000 CA Rotterdam

The Netherlands

E-mail: k.vandenbergh@

erasmusmc.nl

Received:

July 012008

Accepted after revision:

Feb 052009

First published online:

March 122009 
leaflet contained brief information about the aim, background and design of the trial. Current and former smokers were asked to complete the first NELSON questionnaire on smoking history and health. It was explained that those eligible for the NELSON trial would receive an invitation to participate together with detailed information about the trial. Respondents to the first questionnaire who reported to have smoked $>15$ cigarettes $\cdot$ day $^{-1}$ for $>25$ yrs or $>10$ cigarettes. day $^{-1}$ for $>30$ yrs, who still smoked or who had quit $\leqslant 10$ yrs previously were invited to participate in the trial. Exclusion criteria were a self-reported moderate or bad health status in combination with inability to climb two stairs; a history of renal cancer, melanoma or breast cancer; a history of lung cancer diagnosed $<5$ yrs previously, or $>5$ yrs ago but still under treatment; a chest CT examination $<1 \mathrm{yr}$ prior to recruitment; or a body weight $\geqslant 140 \mathrm{~kg}$ [7].

Subjects eligible for trial participation received a second letter with an information brochure and a second NELSON questionnaire, including the informed consent form [7]. The letter was explained that the subject was eligible for the trial and they were asked to read the information brochure carefully. Furthermore, it was explained that the subject had to complete the informed consent form and the second questionnaire if they decided to participate in the trial. The 14-page brochure contained extensive information about the aim, background and design of the trial, the procedures for diagnostic followup, potential unfavourable effects of lung cancer screening, the randomisation procedure, etc. Subjects who completed and signed the informed consent form were subsequently randomised (1:1) to a screening group with three subsequent CT screening rounds, or to a control group without screening.

The trial was approved by the Dutch Ministry of Health (The Hague, The Netherlands) and by the ethics committees of the participating centres. The Ministry of Health gave permission to start the trial after a positive test of the "comprehensibility" of the trial information.

\section{Informed Decision-making study}

For the Informed Decision-making (IDM) study, the present authors were interested in the responses of the subjects at the moment they were actually deciding, or had just made a decision about participation in the NELSON trial. It was decided that this would be the case at 2-3 weeks after sending the second NELSON trial questionnaire with the informed consent form for the NELSON trial (July 2005). A higher response to the IDM questionnaires was expected from subjects who had already decided to participate in the NELSON trial (i.e., who had returned the informed consent for trial participation) than from subjects who had not yet decided about participation in the NELSON trial 2 weeks after the questionnaire had been sent, or who had decided not to participate in the NELSON trial (i.e. did not return the trial informed consent form). Therefore, the subjects who had not returned the informed consent form within 2 weeks were oversampled: 2,100 questionnaires were sent to this group, and a sample of 400 subjects was drawn from the group had already returned the informed consent form to participate in the NELSON trial (fig. 1).

\section{Questionnaires}

Knowledge

A measure of lung cancer (screening) knowledge was developed for this study, based on the items deemed important in guidelines for informed decision-making for screening [12, 16]. There were seven multiple-choice items and 14 statements ("true/false/do not know") related to three domains of knowledge: 1) characteristics of lung cancer screening (seven items); 2) the trial and the test (six items); and 3) lung cancer (eight items) (table 1). Based on MARTEAU et al. [8] and WALD [12], the items on lung cancer screening were considered to be the most relevant for the decision regarding participation. A summary score was calculated by summing the correct responses (2), nearly correct responses (1), and incorrect and missing responses (0), resulting in a score ranging 0-14. Similarly, a scale score summarising all knowledge items was calculated (score range $0-42$ ).

\section{Attitude}

Attitudes towards lung cancer screening were measured using six five-point Likert scales (bad-good, not reassuring-reassuring, beneficial-harmful, important-unimportant, unwise-wise and desirable-undesirable). The choice of items was based on MARTEAU et al. [8] and VAN DEN BERG et al. [11]. The scale score ranged 6-30 with higher scores indicating a more positive attitude.

\section{Risk perception}

Cognitive risk perception was measured using two population risk estimations. Affective risk perception was measured with one item to evaluate how a person felt about his or her risk (table 2).

\section{Reasons to participate or decline}

Reasons to participate in or decline lung cancer screening were assessed using 11 response options for participation and 12 for nonparticipation, based on previous research in prostate cancer screening [17], and the reasons given by subjects in the test of "comprehensibility" of the NELSON trial information. Subjects could also respond "other reasons". Furthermore, they were asked to give their decisive reason. Subjects were also asked whether they had already decided to participate in the trial.

\section{Informed decision}

Following MARTEAU et al. [8], an informed choice (decision) is based on adequate decision-relevant knowledge and a behaviour that is consistent with attitude. Hence, an informed decision to participate is characterised by adequate knowledge, a positive attitude towards lung cancer screening, and actual participation (randomisation in the NELSON trial). An informed decision to decline participation was characterised by adequate knowledge, a negative attitude towards lung cancer screening, and actual nonparticipation. All other combinations were defined as uninformed.

\section{Demographic and other data}

The IDM questionnaire contained items on sex, date of birth, marital status and whether the subject had children. Educational level, smoking status (current and former), and 


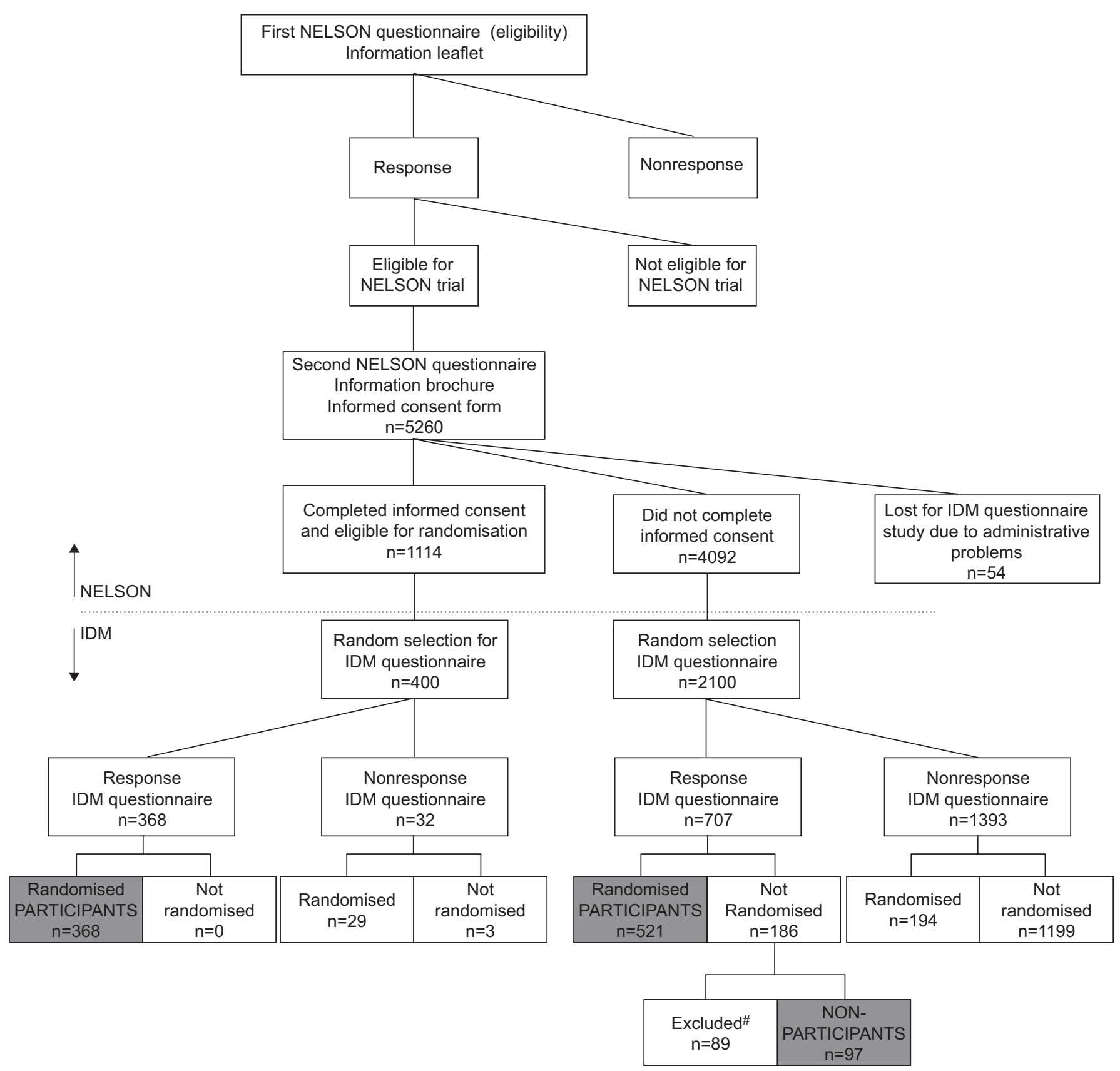

FIGURE 1. Flow chart of data collection for the Dutch-Belgian randomised controlled trial for lung cancer screening in high-risk subjects (NELSON) trial and the Informed Decision-making (IDM) study, with a definition of participants and nonparticipants. \#: these subjects filled in that they "certainly would" participate in the NELSON trail but were not randomised because of an administrative failure (i.e. we never received the informed consent form).

smoking history in pack-yrs were derived from the first NELSON questionnaire.

\section{Statistical analyses}

Subjects with scores above the midpoint of the lung cancer screening knowledge scale $(>7)$, complete knowledge scale $(>21)$ and attitude scale $(>18)$, were classified as having adequate knowledge (first two scores), and a positive attitude (third score), respectively; others were classified as not having adequate knowledge (first two scores), and a negative attitude (third score), respectively [9]. Cronbach's alphas for the three scales were $0.54,0.75$ and 0.83 , respectively. The affective risk perception item was divided into a low affective risk group (response options very low, low, and not low/not high) and a high affective risk group (response options high and very high).

The present study describes two groups. The first $(n=889)$ is the "participant group" of the NELSON trial (fig. 1); they were randomised for the NELSON trial and completed the IDM questionnaire. The second group $(n=97)$ is the "nonparticipant group" of the NELSON trial who completed the IDM questionnaire but were not randomised. Excluded from analysis were 
TABLE 1 Percentages of correct answers on knowledge items of participants $(n=889)$ and nonparticipants $(n=97)$ and significant differences between participants and nonparticipants

\section{Information given in the brochure \\ Characteristics of lung cancer \\ Not mentioned in brochure \\ Not mentioned in brochure \\ Not mentioned in brochure \\ Not mentioned in brochure \\ Not mentioned in brochure \\ Not mentioned in brochure \\ Not mentioned in brochure \\ Not mentioned in brochure}

Knowledge item

(correct answer)
Correct answers $\% \#$

p-value

(participants versus

nonparticipants)

\section{Characteristics of lung cancer screening}

The radiologist reads the CT scans for the existence of lung cancer. No screening for abnormalities in organs other than the lungs will be performed.

A normal CT scan means that no abnormalities suspicious for lung cancer were found. A normal CT scan does not guarantee that lung cancer will never appear.

An abnormality suspicious for lung cancer is found in $2 \%$ of the CT scans

An indeterminate result will be found in $18 \%$ of the CT scans (i.e. an abnormality for which it is unclear whether it is benign or malignant)

The pulmonologist or radiologist will contact you with the result and make appointments for follow-up. You will undergo diagnostic follow-up. You will be referred by your general practitioner to a pulmonologist who will do diagnostic follow-up.

The only way to distinguish between a benign or malignant abnormality is to repeat the CT scan after 3-4 months. You will receive this message by mail.

It is possible that, although the CT scan result was "an abnormality suspicious for lung cancer", after extensive diagnostic research or even surgery, no lung cancer is diagnosed

\section{Characteristics of the trial and the test}

The CT photos are made with X-rays

The research table moves through the arch of the CT scanner. The brochure shows a picture of the CT scanner

To undergo the CT scan, you do not have to undress (but it is necessary to remove all metal objects)

If you are in the screen group, you will be invited for a CT scan three times in the next 4 yrs

One group will not be scanned (control group)
In the past, before the CT scan was introduced, the chance of dying due to lung cancer after diagnosis was... (very high)

Lung cancer is one of the most common

cancers (yes)

A change of cough pattern is a frequent sign of lung cancer (yes)

Coughing up some blood is a frequent sign of lung cancer (yes)

Lung cancer is hereditary (no)

Lung cancer is infectious (no)

A subject can have lung cancer without complaints (yes)

Someone who has quit smoking has a higher risk of developing lung cancer than someone who has never smoked (yes)

For which disorder are subjects being screened by a CT scan in the NELSON trial? (more than one item could be ticked) (lung cancer/all visible disorders on the CT scan)

Meaning of a "normal" CT result (probably/certainly no lung cancer) (false-negative result)

Percentage of subjects with a screen positive CT scan result (2)

Percentage of subjects with an indeterminate screening CT scan result (18)

Follow-up after positive CT scan result (message by phone and referral to pulmonologist for diagnostic follow-up)

Follow-up after indeterminate CT scan result (message by mail and repeat scan after 3-4 months)

When a lung lesion is removed surgically, it is possible that it was not lung cancer (yes)

A CT scan is made with $\mathrm{X}$-rays (yes)

Subjects lie in an enclosed tunnel (no)

For the CT scan you have to undress your upper body (no)

Lung cancer screening is standard for all subjects with a high risk (no)

Subjects in the screen group receive three CT scans (yes)

Subjects in the control group receive one CT scan (no)

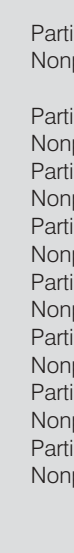

$$
\begin{aligned}
& \mathrm{Pa} \\
& \mathrm{N} o \\
& \mathrm{~Pa} \\
& \mathrm{~N} \\
& \mathrm{P} \\
& \mathrm{N} \\
& \mathrm{Pa} \\
& \mathrm{N} \\
& \mathrm{Pa} \\
& \mathrm{N} \\
& \mathrm{Pa} \\
& \mathrm{N}
\end{aligned}
$$

Original wording was in Dutch: the translations are conceptual, not literal. CT: computed tomography: NELSON: Dutch-Belgian randomised controlled trial for lung cancer screening in high-risk subjects. " : missing answers for the lung cancer screening items, lung cancer items, and for the trial and test items for the participants were: $0.6-1.5 \%, 0.3-2.0 \%$ and $0.7-$ $1.6 \%$, respectively; and for the nonparticipants $5.2 \%-7.6 \%, 4.1 \%-8.2 \%$, and $7.2-11.3 \%$, respectively. A missing answer was counted as an incorrect answer. ${ }^{\prime}$. differences in percentage correct answers were adjusted for sex and smoking status.

89 subjects who completed the IDM questionnaire and intended to participate in the NELSON trial but were not randomised for administrative reasons (e.g. the informed consent form was never received). Chi-squared tests (sex, smoking status) or MannWhitney U-tests (age, smoking history in pack-yrs) were applied to determine the selectivity of questionnaire response among participants and nonparticipants.

Analysis of the differences between participants and nonparticipants was adjusted for sex and smoking status (former/current 
TABLE 2 Cognitive and affective risk perception about lung cancer of participants and nonparticipants

\begin{tabular}{|c|c|c|}
\hline Total subjects $\mathrm{n}$ & 889 & 97 \\
\hline \multicolumn{3}{|c|}{$\begin{array}{l}\text { How do you estimate the chance of an average man getting lung cancer during } \\
\text { his lifetime in the Netherlands? }\end{array}$} \\
\hline Answers $\mathrm{n}$ & 871 & 92 \\
\hline Approximately 1 in 25 (4\%) & 13.8 & 15.2 \\
\hline Approximately 1 in $50(2 \%)$ & 19.2 & 16.3 \\
\hline Approximately 1 in 100 (1\%) & 16.8 & 21.7 \\
\hline Approximately 1 in $250(0.4 \%)$ & 14.5 & 20.7 \\
\hline \multicolumn{3}{|c|}{$\begin{array}{l}\text { How do you estimate the chance of an average woman getting lung cancer during } \\
\text { her lifetime in the Netherlands? }\end{array}$} \\
\hline Approximately 1 in 25 (4\%) & 14.0 & 15.1 \\
\hline Approximately 1 in $50(2 \%)^{\#}$ & 32.1 & 29.0 \\
\hline Approximately 1 in $100(1 \%)$ & 20.4 & 25.8 \\
\hline Approximately 1 in $250(0.4 \%)$ & 19.7 & 18.3 \\
\hline \multicolumn{3}{|l|}{ Affective risk perception } \\
\hline \multicolumn{3}{|c|}{ What do you feel your chance is of developing lung cancer? } \\
\hline Answers $n$ & 884 & 93 \\
\hline Very low & 3.6 & 3.2 \\
\hline Low & 21.5 & 24.7 \\
\hline Not low/not high & 60.5 & 65.6 \\
\hline High & 13.5 & 5.4 \\
\hline Very high & 0.9 & 1.1 \\
\hline
\end{tabular}

Data are presented as $\%$, unless otherwise stated. Original wording was in Dutch: the translations are conceptual, not literal. ${ }^{*}$ : correct answer.

smoker). Logistic regression analysis was used to evaluate differences in response to each knowledge item (correct/ incorrect), in knowledge sum scores (adequate/inadequate), attitudes (positive/negative), lung cancer risk estimations (correct/incorrect), and in affective risk perceptions (high/low).

Multiple logistic regression analysis was used to analyse the association of sex and education with knowledge in the group of participants. The following covariates were included: age, smoking history in pack-yrs, smoking status, sex and education.

Data are presented as mean $\pm \mathrm{SD}$, unless otherwise stated.

\section{RESULTS}

\section{Response and characteristics of the respondents}

For participants in the NELSON trial the response to the IDM questionnaire was $79.9 \%$ (889 out of 1,112 ); for the nonparticipants it was 7.5\%: (97 out of (1388-89); fig. 1$)$.

Table 3 shows the characteristics of the NELSON subjects selected for the IDM study (participants and nonparticipants), and the characteristics of the IDM respondents from among the NELSON participants and NELSON nonparticipants. The nonparticipants showed a low response rate. Females from the nonparticipants group responded more often than males $(p=0.003)$ and former smokers from the nonparticipants group responded more often than current smokers $(\mathrm{p}=0.035)$. At the time of completion of the IDM questionnaire, $0.5 \%$ of the participants and $4.2 \%$ of the nonparticipants were undecided about their participation in the trial.

\section{Knowledge}

Responses to the lung cancer items were more often correct than responses to lung cancer screening items and responses to the trial and the test items (table 1 ). On average, $67.7 \pm 17.1 \%$ of the participants' responses to the knowledge items relating to lung cancer as a disease were correct, and $54.4 \pm 9.8 \%$ of their responses to knowledge items relating to the trial and the test were correct. Responses to items relating to lung cancer screening were the least often correct $48.6 \pm 28.9 \%$.

About one-third of the participants responded "Do not know" to the item about how often a positive or indeterminate result would be obtained. About $40 \%$ underestimated the number of indeterminate results of the CT scan; more than $50 \%$ thought that they would be referred to a pulmonologist after such a result. Only $16.9 \%$ knew that it might be possible that a surgically removed lung lesion could be benign (false-positive result).

Participants significantly more often exhibited a correct item response to 12 of the 21 items (table 1 ). 


\begin{tabular}{|c|c|c|c|c|}
\hline Subjects $n$ & 1112 & 1299 & 889 & 97 \\
\hline Sex male \% & 49.6 & 47.7 & 48.5 & 33.0 \\
\hline \multicolumn{5}{|l|}{ Education } \\
\hline Primary education \% & 9.3 & 15.5 & 8.6 & 15.5 \\
\hline $\begin{array}{l}\text { Lower vocational or lower secondary general } \\
\text { education \% }\end{array}$ & 40.0 & 43.2 & 41.3 & 38.1 \\
\hline $\begin{array}{l}\text { Intermediate vocational or higher secondary } \\
\text { general education \% }\end{array}$ & 24.4 & 22.7 & 24.5 & 22.7 \\
\hline Current smokers \% & 43.6 & 46.4 & 43.0 & 36.1 \\
\hline Smoking history pack-yrs & $40.6 \pm 17.9(38.0)$ & $40.2 \pm 17.3(38.0)$ & $40.4 \pm 17.9(35.8)$ & $39.4 \pm 16.5(34.2)$ \\
\hline $\begin{array}{l}\text { Have you decided yet whether to participate } \\
\text { in the NELSON trial? } n\end{array}$ & & & 864 & 95 \\
\hline Yes, certainly \% & & & 93.6 & NA \\
\hline Yes, certainly not \% & & & 0.0 & 65.3 \\
\hline I am still in doubt, but probably yes \% & & & 5.8 & 15.8 \\
\hline I am still in doubt, but probably no \% & & & 0.3 & 14.7 \\
\hline I do not know yet \% & & & 0.2 & 4.2 \\
\hline
\end{tabular}

Data are presented as mean $\pm S D$ (median), unless otherwise stated. Original wording was in Dutch: the translations are conceptual, not literal. NELSON: Dutch-Belgian randomised controlled trial for lung cancer screening in high-risk subjects; NA: not applicable. ${ }^{\#}$ : excluded were 89 subjects who intended to participate in the NELSON trial and completed the IDM questionnaire, but were not randomised for administrative reasons (i.e. informed consent form was never received). ${ }^{`}$ : all participants are ever-smokers.

The participants' responses more often reflected adequate knowledge regarding lung cancer screening (51.4\%: 432 out of $889)$ than the responses from nonparticipants (38.1\%: 37 out of 97; $\mathrm{p}=0.009)$. When knowledge about lung cancer and about the trial was included in the knowledge sum score, then $72.7 \%$ (646 out of 889 ) of the participants and $53.6 \%$ (52 out of 97) of the nonparticipants had adequate knowledge $(p<0.0005)$.

The percentage of correct responses was significantly higher in females and higher-educated participants compared to males and lower-educated participants in seven and eight out of the 21 knowledge items, respectively (table 4).

\section{Attitude}

Participants more often showed a positive attitude $(98.7 \%)$ than the nonparticipants $(63.8 \% ; \mathrm{p}<0.0005)$.

\section{Risk perception}

About one-third of participants made a correct estimation of the risk for an average male/female in the Netherlands to develop lung cancer during their lifetime (table 2). No differences were found between participants and nonparticipants. Participants (14.4\%) more often reported their opinion of their risk of developing lung cancer as high or very high than the nonparticipants $(6.5 \% ; \mathrm{p}=0.049)$.

\section{Reasons to participate or decline}

About $80 \%$ of the participants mentioned "I may have an advantage if lung cancer is detected in an early stage", and "Smoke(d) much" as a reason for participation (table 5).

Almost half of the nonparticipants mentioned "Participation too much effort" as one of the reasons to decline participation (table 6$) ; 14.5 \%(n=12)$ gave other reasons, e.g. that they already had regular examination for something else, or were anxious.

\section{Informed decision}

Using only knowledge of lung cancer screening, 51.3\% of the participants (427 out of 832) made an informed decision to participate. When using all knowledge items, 72.7\% (605 out of 832) made an informed decision to participate.

\section{DISCUSSION}

The results of this study show that, when deciding to participate in a lung cancer screening trial, the knowledge of subjects was fairly good with regard to lung cancer but only moderate with regard to lung cancer screening itself. In general, nonparticipants had less knowledge than participants. Nonparticipants' attitudes towards lung cancer screening were less positive than those of participants, but they were still positive for two-thirds of the nonparticipants. Participants had 


\section{TABLE 4 Differences in correct answers on knowledge items between males and females and high/low education among participants $(n=889)$}

\section{Characteristics of lung cancer}

In the past, before the CT scan was introduced, the chance of dying due to lung cancer after diagnosis was... (very high)

Lung cancer is one of the most common cancers (yes)

A change of cough pattern is a frequent sign of lung cancer (yes)

Coughing up some blood is a frequent sign of lung cancer (yes)

Lung cancer is hereditary (no)

Lung cancer is infectious (no)

A subject can have lung cancer without complaints (yes)

Someone who has quit smoking has a higher risk of developing lung cancer than someone who has never smoked (yes)

\section{Characteristics of lung cancer screening}

For which disorder(s) are subjects being screened by a CT scan in the NELSON trial? (more than one item could be ticked) (lung cancer/all visible disorders on the CT scan)

Meaning of a "normal" CT result (probably/certainly no lung cancer)

Percentage of subjects with a screen positive CT scan result (2)

Percentage of subjects with an indeterminate screening CT scan result (18)

Follow-up after positive CT scan result (message by phone and referral to pulmonologist for diagnostic follow-up)

Follow-up after indeterminate CT scan result (message by mail and repeat scan after 3-4 months)

When a lung lesion is removed surgically, it is possible that it was not lung cancer (yes)

\section{Characteristics of the trial and the test}

A CT scan is made with $X$-rays (yes)

Subjects lie in an enclosed tunnel (no)

For the CT scan you have to undress your upper body (no)

Lung cancer screening is standard for all subjects with a high risk (no)

Subjects in the screen group receive three CT scans (yes)

Subjects in the control group receive one CT scan (no)

$\begin{array}{ll}1.25(0.94-1.65) & 0.85(0.65-1.15) \\ 0.96(0.72-1.28) & 1.22(0.92-1.62) \\ 1.40(1.04-1.88)^{*} & 1.27(0.95-1.70) \\ 1.35(1.03-1.78)^{*} & 1.03(0.79-1.36) \\ 0.76(0.57-1.01) & 1.29(0.97-1.71) \\ 1.10(0.50-2.41) & 2.95(1.22-7.14)^{*} \\ 1.22(0.85-1.75) & 1.67(1.16-2.41)^{*} \\ 1.15(0.87-1.54) & 1.66(1.24-2.21)^{*}\end{array}$

$1.02(0.76-1.37)$

$0.91(0.68-1.22)$

$1.15(0.64-2.09)$

$0.99(0.55-1.79)$

$1.30(0.97-1.73)$

$1.41(1.01-1.95)^{\star}$

$1.30(0.97-1.74)$

$1.66(1.24-2.23)$ *

$1.22(0.92-1.62)$

$1.15(0.87-1.52)$

$1.55(1.07-2.23)^{*}$

$1.07(0.74-1.54)$

$1.06(0.80-1.39)$

$1.30(0.99-1.71)$

$1.12(0.85-1.48)$

$1.19(0.90-1.56)$

$1.82(1.36-2.45)^{*}$

$1.45(1.11-1.92)^{*}$

$1.50(1.14-1.97)^{*}$

Data are presented as OR (95\% Cl). Original wording was in Dutch: the translations are conceptual, not literal. CT: computed tomography; NELSON: Dutch-Belgian randomised controlled trial for lung cancer screening in high-risk subjects. ${ }^{*}$ : ORs reflect the odds of a female having a correct answer divided by the odds of a male having a correct answer, adjusted for age category (<57 or $>57$ yrs), education (low and high education), smoking history in pack-yrs and smoking status (current or former) in a logistic regression model; ${ }^{\prime}$ : ORs reflect the odds of someone with a high education having a correct answer divided by the odds of someone with a low education having a correct answer, adjusted for age category ( $<57$ or $>57$ yrs), education (low and high education), smoking history in pack-yrs and smoking status (current or former) in a logistic regression model. *: $p<0.05$

a higher perceived risk of developing lung cancer than did nonparticipants. Due to their low knowledge level regarding lung cancer screening, only half of the participants made an informed decision to participate.

\section{Knowledge}

The present results again illustrate the difficulties in getting information on cancer screening across to screening invitees [17, 18]. In Sweden, one-third of cervical cancer screening attendees were unaware of the type of cancer for which they were being screened [19]. Participants in a prostate cancer screening study also had limited knowledge about the meaning of the test results [20]. The results of the present study also confirm the findings of previous cancer screening studies that showed a better knowledge among participants than nonparticipants [14, 21]. For example, participants in a prostate cancer trial were more aware than nonparticipants that someone can have cancer without having symptoms [17].
In the present study, responses to knowledge items relating to lung cancer as a disease were more often correct than responses to items relating to lung cancer screening, the trial and the test. The brochure did not contain detailed information on lung cancer as a disease, whereas information relating to screening, the trial and the test was present. Apparently, these subjects eligible for lung cancer CT screening already had a relatively good general knowledge of lung cancer.

\section{Attitude}

The result that almost all participants and about two-thirds of nonparticipants had a positive attitude towards lung cancer screening is not surprising, since people are generally enthusiastic about cancer screening [4, 22].

\section{Risk perception}

It has been shown that a higher perceived risk for lung cancer is associated with more interest and willingness to be screened 


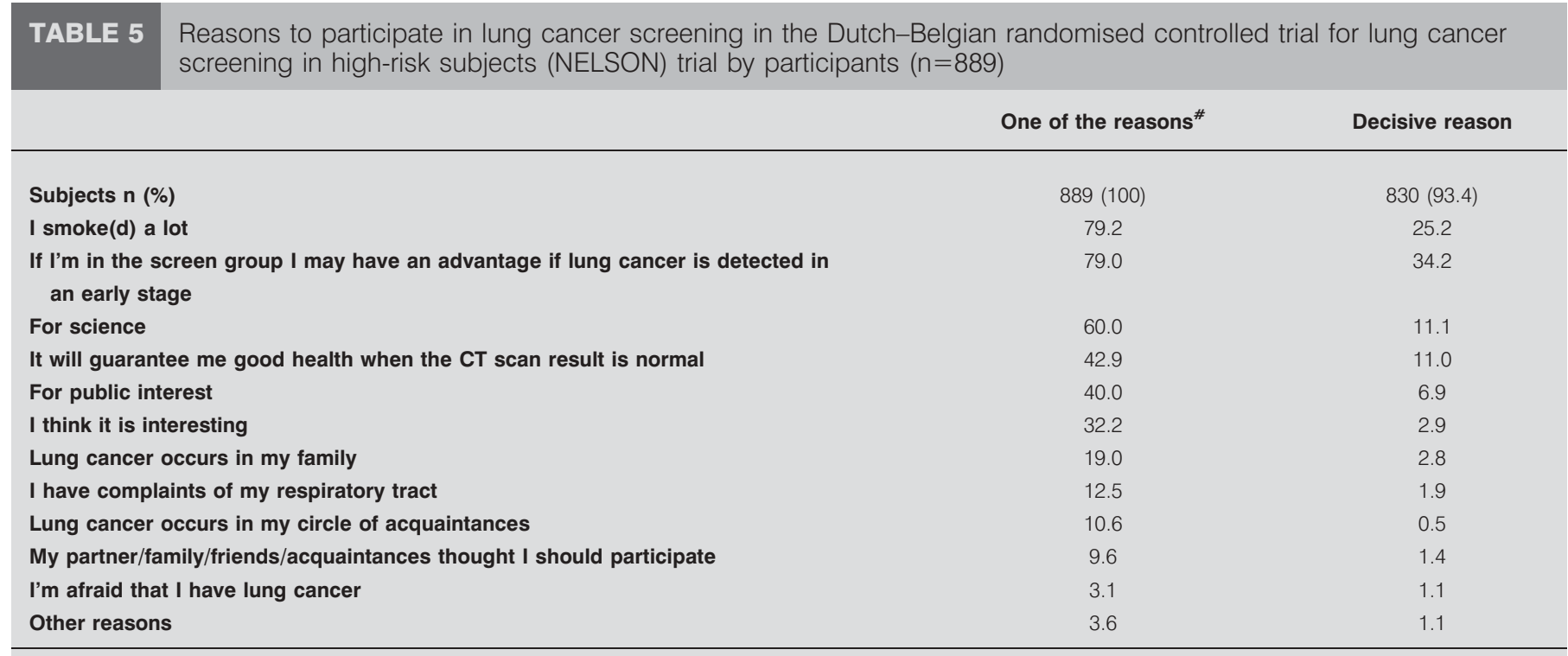

Data are presented as \%, unless otherwise stated. Original wording was in Dutch: the translations are conceptual, not literal. CT: computed tomography. ${ }^{\#}$ : more than one item could be ticked; mean \pm SD number of ticked reasons was $3.9 \pm 1.4$.

for lung cancer $[23,24]$. The results of our study showed that participants had a higher affective risk perception than nonparticipants but not a higher cognitive risk perception. Nevertheless, most subjects underestimated the risk of lung cancer in men and women, and only $14 \%$ of the participants and $6.5 \%$ of the nonparticipants experienced their risk of developing lung cancer as being high.

\section{Reasons to participate or decline}

Reasons for participation were comparable with those for prostate cancer screening, especially regarding the most important reason, i.e. the possibility of personal benefit $[17,19]$. For
$20 \%$ of the nonparticipants, "Having no complaints of the respiratory tract" was one of the reasons to decline participation in the trial. Although this is lower than in a prostate cancer screening trial $(41 \%)$, subjects should be aware that someone can have lung cancer without complaints [17]. For cervical cancer screening, an important reason to decline was a lack of confidence in the benefits of screening $[19,25]$.

\section{Informed Decision-making}

The percentage of informed decisions depended on which knowledge scale we used. Based on responses to items relating to lung cancer, screening, and the trial and the test,

TABLE 6 Reasons to decline participation in lung cancer screening in the Dutch-Belgian randomised controlled trial for lung cancer screening in high-risk subjects (NELSON) trial by non-participants $(n=97)$

\begin{tabular}{|c|c|c|}
\hline & One of the reasons ${ }^{\#}$ & Decisive reason \\
\hline Subjects n (\%) & $93(95.9)$ & $83(89.2)$ \\
\hline I don't have enough insight into the personal consequences of the test & 30.1 & 19.3 \\
\hline I don't have complaints of my respiratory tract & 20.4 & 7.2 \\
\hline l'd rather not undergo a CT scan & 18.3 & 10.8 \\
\hline Because of reasons "on principle" & 4.3 & 1.2 \\
\hline I'm afraid that I have lung cancer & 3.2 & 2.4 \\
\hline I have complaints of my respiratory tract & 4.3 & 1.2 \\
\hline I think it is not interesting & 2.2 & 2.4 \\
\hline Lung cancer occurs in my family & 2.2 & 0 \\
\hline Information in the brochure is not clear enough & 1.1 & 0 \\
\hline
\end{tabular}

Data are presented as \%, unless otherwise stated. Original wording was in Dutch: the translations are conceptual, not literal. CT: computed tomography. ${ }^{\#}$ : more than one item could be ticked; mean \pm SD number of ticked reasons was $1.8 \pm 0.9$. 
approximately $70 \%$ made an informed decision. Restricting the knowledge scores to items relating to lung cancer screening (that are deemed to reflect the most relevant knowledge concerning decision-making), only 50\% made an informed decision to participate $[12,16]$. The levels of informed decisionmaking were almost completely determined by knowledge, since almost all participants had a positive attitude towards lung cancer screening.

\section{Limitations}

Nonparticipants showed a low response rate to the IDM questionnaire and the response came from a selected group. However, comparisons could be made between participants and nonparticipants because we could adjust for sex and smoking status. Although these results have to be interpreted with caution, we consider the results of the analyses to be potentially useful.

Sending reminders and posting the questionnaire at a different time of the year (e.g. avoiding the summer vacation period) might have improved the response. However, studies that did this still showed low response rates among nonparticipants, and selective response remains hard to avoid among nonparticipants $[17,26]$.

Because a decision about participating in a screening programme is different from deciding to participate in a trial, the results of the present study might not be generalisable to the general population at risk for lung cancer, or to the situation when lung cancer screening may be implemented as a population-based screening programme. However, it is expected that trial subjects will read and try to understand the trial information better than the information of an established screening programme [11]. Moreover, some subjects may not want to participate in a trial, but may do so in case of an established programme. Effects of IDM are speculative, because a prenatal screening study showed evidence for a decrease of IDM when the screening is part of standard practice [27].

Although the present study aimed to measure attitudes and knowledge at a time when the subjects were in the decisionmaking process, almost all subjects had already made their decision to participate or decline participation. Apparently, decision-making takes place soon after receipt of the invitation. Knowledge may have been better at the moment they made their decision about participation, because many people cannot recall information given shortly beforehand, and knowledge generally decreases over time [13, 28]. Nevertheless, we consider it important that people remember the essential facts about lung cancer screening after their decision has been made.

\section{Implications}

Improving knowledge about lung cancer screening of subjects eligible for CT screening is necessary, because an inappropriate understanding of the screening test results may increase the negative psychosocial effects [18]. Although most topics were mentioned in the brochure, $51 \%$ of the subjects showed inadequate knowledge. Some participants were over-optimistic about the CT scan (e.g. it represents a guarantee for good health). Improving the content of the brochure is a possibility. However, although a brochure may not be the best way to convey information [14, 29], how to improve the transfer of information still needs to be determined [10, 14]. It remains unclear whether written or verbal information, videotape, decision aids or the internet may be the method for this.

However, there is a growing belief that not all subjects who are offered screening should be forced to informed decisionmaking [10, 30]. As IRWIG et al. [10] recently stated: “ ... all those eligible for screening should be aware of the screening program and have received and understood an agreed minimum of information about benefits and harms of the procedure so that they can decide whether to follow the advice of an authoritative health body or make an individual choice". This means that, on the one hand, we have to acknowledge that not all subjects are able/want to make an informed decision by rational deliberation and, on the other, that everyone who makes a decision should have at least a minimum level of knowledge [10, 13, 28, 30]. Then, the critical question is: what precisely constitutes "adequate (decision relevant) knowledge", and who decides what that is [31]."

\section{Conclusions}

Only about half of the participants in the NELSON trial made an informed decision. If population-based lung cancer screening is to be implemented, then additional effort is needed to convey essential knowledge to subjects who are in the process of decision-making about participation in lung cancer screening.

\section{CLINICAL TRIAL}

The NELSON trial was registered at the Netherlands Trial Register (www.trialregister.nl) with number ISRCTN63545820.

\section{SUPPORT STATEMENT}

The present study was funded by the Netherlands Organisation for Health Research and Development (ZonMw; The Hague, The Netherlands; grant number 2200.0130), the Dutch Cancer Society (KWF; Amsterdam, The Netherlands; grant number EMCR 2001-2371) and the Health Insurance Innovation Foundation (Innovatiefonds Zorgverzekeraars; Zeist, The Netherlands). The funding sources had no involvement in the work.

\section{STATEMENT OF INTEREST}

None declared.

\section{ACKNOWLEDGEMENTS}

The authors thank C.A. van Iersel (Erasmus MC, Rotterdam, The Netherlands) for her contribution in formulating the knowledge items, C. van der Aalst (Erasmus MC) for recoding the written answers to the reason items, and A.C. de Jongh (Artex BV, Capelle aan den IJssel, The Netherlands) for his contributions to the selection of participants and the handling of the mailings.

\section{REFERENCES}

1 Ferlay J, Bray F, Pisani P, et al., GLOBOCAN 2002: Cancer Incidence, Mortality and Prevalence Worldwide. IARC CancerBase No. 5. version 2.0., vol 2005. Lyon, IARCPress, 2004.

2 American Cancer Society. Cancer Facts \& Figures 2007. Atlanta, American Cancer Society, 2007. www.cancer.org/downloads/ STT/CAFF2007PWSecured.pdf Date last accessed: June 26, 2008.

3 Henschke CI, Yankelevitz DF, Libby DM, et al. Survival of patients with stage I lung cancer detected on CT screening. N Engl J Med 2006; 355: 1763-1771. 
4 Schwartz LM, Woloshin S, Fowler FJ Jr, et al. Enthusiasm for cancer screening in the United States. JAMA 2004; 291: 71-78.

5 Bach PB, Jett JR, Pastorino U, et al. Computed tomography screening and lung cancer outcomes. JAMA 2007; 297: 953-961.

6 Gohagan J, Marcus P, Fagerstrom R, et al. Baseline findings of a randomized feasibility trial of lung cancer screening with spiral CT scan vs chest radiograph: the Lung Screening Study of the National Cancer Institute. Chest 2004; 126: 114-121.

7 van Iersel CA, de Koning HJ, Draisma G, et al. Risk-based selection from the general population in a screening trial: selection criteria, recruitment and power for the Dutch-Belgian randomised lung cancer multi-slice CT screening trial (NELSON). Int J Cancer 2007; 120: 868-874.

8 Marteau TM, Dormandy E, Michie S. A measure of informed choice. Health Expect 2001; 4: 99-108.

9 Michie S, Dormandy E, Marteau TM. The multi-dimensional measure of informed choice: a validation study. Patient Educ Couns 2002; 48: 87-91.

10 Irwig L, McCaffery K, Salkeld G, et al. Informed choice for screening: implications for evaluation. BMJ 2006; 332: 1148-1150.

11 van den Berg M, Timmermans DR, Ten Kate LP, et al. Are pregnant women making informed choices about prenatal screening? Genet Med 2005; 7: 332-338.

12 Wald N. Information leaflets in medical screening. J Med Screen 2006; 13: 109.

13 Jepson RG, Hewison J, Thompson AG, et al. How should we measure informed choice? The case of cancer screening. J Med Ethics 2005; 31: 192-196.

14 Hewitson P, Austoker J. Part 2: Patient information, informed decision-making and the psycho-social impact of prostate-specific antigen testing. BJU Int 2005; 95: Suppl. 3, 16-32.

15 Philips Z, Avis M, Whynes DK. Knowledge of cervical cancer and screening among women in east-central England. Int J Gynecol Cancer 2005; 15: 639-645.

16 General Medical Council. Seeking patients' consent: the ethical considerations. London, General Medical Council, 1998. www. gmc-uk.org/guidance/archive/Seeking $\% 20$ patients $\% 20$ consent $\% 20$ The $\% 20$ ethical\%20considerations.pdf. Date last accessed: June 26, 2008.

17 Nijs HG, Essink-Bot ML, DeKoning HJ, et al. Why do men refuse or attend population-based screening for prostate cancer? J Public Health Med 2000; 22: 312-316.

18 Fylan F. Screening for cervical cancer: a review of women's attitudes, knowledge, and behaviour. Br J Gen Pract 1998; 48: 1509-1514.
19 Idestrom M, Milsom I, Andersson-Ellstrom A. Knowledge and attitudes about the Pap-smear screening program: a populationbased study of women aged 20-59 years. Acta Obstet Gynecol Scand 2002; 81: 962-967.

20 Watson E, Hewitson P, Brett J, et al. Informed decision making and prostate specific antigen (PSA) testing for prostate cancer: A randomised controlled trial exploring the impact of a brief patient decision aid on men's knowledge, attitudes and intention to be tested. Patient Educ Couns 2006; 63: 367-379.

21 Briss P, Rimer B, Reilley B, et al. Promoting informed decisions about cancer screening in communities and healthcare systems. Am J Prev Med 2004; 26: 67-80.

22 Livingston P, Wakefield M, Elwood JM. Community attitudes towards the early detection of cancer in Victoria, Australia. Aust NZ J Public Health 2007; 31: 26-29.

23 Hahn EJ, Rayens MK, Hopenhayn C, et al. Perceived risk and interest in screening for lung cancer among current and former smokers. Res Nurs Health 2006; 29: 359-370.

24 Schnoll RA, Bradley P, Miller SM, et al. Psychological issues related to the use of spiral CT for lung cancer early detection. Lung Cancer 2003; 39: 315-325.

25 Blomberg K, Ternestedt BM, Törnberg S, et al., How do women who choose not to participate in population-based cervical cancer screening reason about their decision? Psychooncology 2008; 17: 561-569.

26 Eborall HC, Griffin SJ, Prevost AT, et al. Psychological impact of screening for type 2 diabetes: controlled trial and comparative study embedded in the ADDITION (Cambridge) randomised controlled trial. Br Med J 2007; 335: 486.

27 Dormandy E, Hooper R, Michie S, et al. Informed choice to undergo prenatal screening: a comparison of two hospitals conducting testing either as part of a routine visit or requiring a separate visit. J Med Screen 2002; 9: 109-114.

28 Rimer BK, Briss PA, Zeller PK, et al. Informed decision making: what is its role in cancer screening? Cancer 2004; 101: Suppl., 1214-1228.

29 National Cancer Institute (NCI). Designing print materials: A communications guide for breast cancer screening. NIH Publication No. 07-6100. Bethesda, National Institutes of Health, 2007. http://appliedresearch.cancer.gov/icsn/manual.pdf.

30 Entwistle VA, Carter SM, Trevena L, et al. Communicating about screening. Br Med J 2008; 337: a1591.

31 Green JM, Hewison J, Bekker HL, et al. Psychosocial aspects of genetic screening of pregnant women and newborns: a systematic review. Health Technol Assess 2004; 8: 1-109. 